\title{
BMJ Open Psychometric properties of the Norwegian version of the short form of The Problem Areas in Diabetes scale (PAID-5): a validation study
}

\author{
Maarja Vislapuu, ${ }^{1}$ Anders Broström, ${ }^{1,2,3}$ Jannicke Igland, ${ }^{1,4}$ Allison Vorderstrasse ${ }^{5}$ \\ Marjolein M Iversen ${ }^{1}$
}

To cite: Vislapuu M, Broström A, Igland J, et al. Psychometric properties of the Norwegian version of the short form of The Problem Areas in Diabetes scale (PAID-5): a validation study. BMJ Open 2019;9:e022903. doi:10.1136/ bmjopen-2018-022903

\section{- Prepublication history and} additional material for this paper are available online. To view these files, please visit the journal online (http://dx.doi. org/10.1136/bmjopen-2018022903).

Received 28 March 2018 Revised 8 November 2018 Accepted 18 December 2018

Check for updates

(C) Author(s) (or their employer(s)) 2019. Re-use permitted under CC BY-NC. No commercial re-use. See rights and permissions. Published by BMJ.

For numbered affiliations see end of article.

Correspondence to

Professor Marjolein M Iversen; miv@hvl.no

\section{ABSTRACT}

Objectives To assess the psychometric properties of the short form of The Problem Areas in Diabetes scale (PAID-5) in Norwegian adult patients with type 1 or type 2 diabetes. Design Cross-sectional survey design.

Methods Participants $(n=143)$ were included from three Western-Norway endocrinology outpatient clinics. Demographic and clinical data were collected in addition to questionnaires concerning diabetes-related distress, fear of hypoglycaemia, symptoms of depression, emotional well-being and perception of general health. Psychometric evaluation of the PAID-5 included confirming its postulated one-factor structure using confirmatory factor analysis (CFA) and assessing convergent validity, discriminant validity, internal consistency and test-retest reliability. The retest questionnaire was sent out $35 \pm 15$ days after the initial assessment to those who agreed $(n=117)$.

Results The CFA for the PAID- 5 scale showed excellent one-factor structure, and there was high internal consistency $(\alpha=0.89)$ and good test-retest reliability (Intraclass Correlation Coefficient, ICC $=0.81$ ). The PAID-5 correlated positively with fear of hypoglycaemia $(r=0.598)$ and depression $(r=0.380)$ and negatively with emotional well-being $(r=-0.363)$ and perception of general health $(r=-0.420)$, thus satisfying convergent validity. Patients who had experienced episodes of serious hypoglycaemia in the past 6 months had a significantly higher PAID-5 mean score $(7.5, S D=4.95)$ than those who had not had these episodes $(5.0, S D=4.2(p=0.043))$.

Conclusion The Norwegian PAID-5 was shown to be a reliable and valid short questionnaire for assessing diabetes-related distress among people with type 1 or type 2 diabetes. However, its ability to discriminate between groups needs to be tested further in larger samples. The PAID-5 scale can be a particularly valuable screening instrument in outpatient clinics, as its brevity makes it easy to use as a tool in patient-provider encounters. This short questionnaire is useful in the national diabetes registry or population cohort studies as it enables increased knowledge regarding the prevalence of diabetes-related distress.

\section{INTRODUCTION}

The International Diabetes Federation ${ }^{1}$ states that diabetes is one of the largest global health
Strengths and limitations of this study

- The Norwegian Problem Areas in Diabetes scale (PAID-5) demonstrated good psychometric properties, enabling the assessment of diabetes-related emotional distress.

- The non-responders were younger than the participants, which calls for caution when interpreting the results for younger adults with diabetes.

- The sample size restricted us in determining if the PAID- 5 scale has the ability to discriminate between different subgroups.

- Further testing in a larger sample is required.

emergencies of the 21st century and that by the year 2045 an estimated 628.6 million people will have diabetes, which is $9.9 \%$ of the total world population. In Norway, the prevalence of type 2 diabetes increased from $4.9 \%$ to $6.1 \%$ between 2009 and $2014 .^{2}$ After Finland and Sweden, Norway is among the countries with the highest incidence of childhood-onset type 1 diabetes in the world and the average incidence rate was 32.7 per 100000 person-years from 2004 to 2012. ${ }^{3}$ The Diabetes Control and Complications Trial showed that inadequate quality of diabetes care contributes to an increased risk for developing a number of serious and disabling health problems among people with type 1 diabetes. ${ }^{4}$ The United Kingdom Prospective Diabetes Study showed similar results among people with type 2 diabetes. ${ }^{5}$

The daily demands of diabetes, as a chronic disease, have a negative impact on physical health and on psychological health. ${ }^{6}$ The complex nature of diabetes itself, acute fluctuations in blood glucose levels and the fear of long-term complications lead to high levels of subclinical diabetes-specific distress. ${ }^{7}$ Diabetes distress is part of the experience of diabetes for many patients over time. ${ }^{89}$ Even 
at low levels, diabetes distress has been shown to be related to glycaemic control and behavioural management. ${ }^{8} 10$ People with diabetes make far more health management decisions compared with healthcare personnel, and the needs of the person with diabetes including attention to emotional distress must be addressed in the clinical setting. ${ }^{11}$

The cross-national Diabetes Attitudes, Wishes and Needs (DAWN) study showed that almost half of the study population had a high level of diabetes-related distress. ${ }^{6}$ High levels of diabetes-related distress have been linked to medication non-adherence, higher HbAlc, lower self-efficacy and poor dietary and exercise behaviours that lead to poor health outcomes. ${ }^{12}$ Screening for diabetes-specific distress is important in a clinical setting and has been recommended at key time points in the care pathway such as diagnosis, annual medical appointments and inpatient episodes, when complications arise and when issues of glycaemic control or self-management arise. ${ }^{13}$ Therefore, healthcare personnel need to have validated tools to assess patients' perceived diabetes-specific distress.

The PAID-20 is a valid 20-item scale to measure the overall level of diabetes-related emotional distress, developed in the USA. ${ }^{14}$ Each item represents a unique area of diabetes-related psychological stress and higher scores indicate greater emotional diabetes-related distress. The validation study of the PAID-20 questionnaire conducted in Norway showed sufficient reliability and validity among adults with type 1 and type 2 diabetes. ${ }^{15}$ A shorter version of the PAID, which has five items (The Problem Areas in Diabetes scale (PAID-5)), was developed as a tool that can be used for rapid screening of diabetes-related distress both in a clinical setting and in research studies. ${ }^{16}$ The brevity of the PAID-5 may impose a lower burden on patients with diabetes and represents efforts to increase the clinical usefulness of the original scale ${ }^{17}$ as the length and unclear factor structure of the PAID-20 have been identified as shortcomings. ${ }^{17} 18$ The PAID-5 has been validated among people with type 2 diabetes in Korea ${ }^{19}$ and among people with type 1 and type 2 diabetes in the multicultural DAWN study. ${ }^{16}$ In both studies, the PAID-5 showed good reliability and validity. ${ }^{16}{ }^{19}$ As research concerning diabetes and the associated psychological burden continues to receive more attention from researchers, healthcare providers and patients, the availability of sound instruments is important for screening, and to compare different cultures and populations on a global basis. However, a questionnaire that is not properly translated and culturally adapted will be a threat to validity and reliability. Empirical testing of validity and reliability should follow the translation and cultural adaptation phase. ${ }^{20}$ There is still limited knowledge of the psychometric properties of the PAID-5 scale in Europe, in particular the factor structure of the PAID$5 .{ }^{161719}$ As there is a need for a short diabetes distress questionnaire in the Norwegian Diabetes Registry for Adults as well as in population based cohort studies, this needs to be explored.

\section{Aim}

The aim of this study was to examine the psychometric properties of the PAID-5 scale. We hypothesised that PAID-5 scores would be positively associated with worry about hypoglycaemia and symptoms of depression, as variants of the same construct, and negatively associated with the perception of general health and emotional wellbeing. The associations between PAID-5 scores and demographic (age, gender) and clinical variables (HbAlc, duration of diabetes, insulin therapy, diabetes-related complications and episodes of serious hypoglycaemia) were examined. We hypothesised that the PAID-5 scores would discriminate between diabetes-related emotional distress at a group level for gender, insulin regimen and presence of diabetes long-term complications. The reliability of the PAID-5 scale was examined by its internal consistency and test-retest reliability. We also tested the unidimensionality of the PAID-5 questionnaire.

\section{METHODS \\ Design, sample and setting}

A cross-sectional survey design was used to collect data from three Western-Norway endocrinology outpatient clinics between October 2016 and March 2017 by using a consecutive sampling strategy. According to a MonteCarlo simulation study on estimation of sample size for confirmatory factor analysis (CFA), 190 cases are required for a one-factor model with four items and standardised loadings equal to 0.5 , while a model with six items and the same loadings requires a sample size of $90 .{ }^{21}$ Given that the PAID-5 has five items, the minimum required sample size in our study was determined to be between 90 and 190. We included more participants than needed based on the power analysis, because of the possibility for a low response rate. Therefore, 341 patients who met the inclusion criteria were invited to participate in the study. Patients were considered eligible for participation if they were diagnosed with type 1 or type 2 diabetes more than 1 year ago, were between 18 and 65 years old, had the mental capacity to participate and were able to read and write in Norwegian language. We included only patients diagnosed with type 1 or type 2 diabetes more than 1 year ago, as patients may have more diabetes distress adapting to living with diabetes in the first year. Patients with gestational diabetes, short life expectancy or terminal illness and patients who were not able to give informed consent due to some serious mental illness or cognitive disorder were excluded.

\section{Data collection procedure}

Patients meeting the inclusion criteria received the questionnaire (68 questions in total) by mail, an information letter, a consent form to accept, prepaid envelopes and stamps. To examine the stability of the PAID-5 measurement, the retest questionnaire was sent out $35 \pm 15$ days after the first assessment to those who agreed $(n=117)$. 


\section{Measures}

The questionnaire included questions on demographic and clinical characteristics: age, gender, duration of diabetes, diabetes treatment (using insulin and/or oral glucose-lowering agents), episodes of serious hypoglycaemia (needing help from others) in the last 6 months, and the presence of diabetes long-term complications (cardiovascular diseases, retinopathy and foot ulcers). The most recent $\mathrm{HbA}_{1 \mathrm{c}}$, taken in close connection to the data collection, was obtained from medical records, as a measure of metabolic control. $\mathrm{HbA}_{1 \mathrm{c}}$ values older than 8 weeks prior and more than 12 weeks after filling out the survey were excluded.

The questionnaire included the overall question of the RAND-36 scale to assess perceptions of general health ('In general, how would you say your health is?'). Responses were rated on a Likert scale from 1 (excellent) to 5 (poor). Higher scores indicate poorer health. ${ }^{22}$

The HAD-scale is a measure for screening symptoms of anxiety and depression. ${ }^{23}$ In the current study, we used only the HADS-D scale with seven self-report items measuring general symptoms of depression. Responses are rated on a 4-point Likert scale from 0 (not a problem) to 3 (a serious problem). Higher scores indicate higher levels of depressive symptoms. According to Bjelland et $a l,{ }^{24}$ the validity of the HAD scale generally has been good to very good. The Norwegian version of the HAD-scale has shown good psychometric properties in terms of its two-factor structure, intercorrelation of the subscales (variance of $24 \%-36 \%$ ) and internal consistency $(\alpha=0.73-0.85) .^{25}$

The WHO-5 questionnaire monitors a person's level of emotional well-being. This generic unidimensional instrument includes five positively worded items, rated on a 6-point Likert scale. Higher scores indicate better well-being. The WHO-5 questionnaire has been shown to be a psychometrically sound instrument among patients with type 1 and type 2 diabetes in terms of its one-factor structure, interitem correlations (0.71-0.84) and internal consistency $(\alpha=0.91$ and 0.93$) .^{26} 27$

The Hypoglycemia Fear Survey II (HFS-II) has two subscales (33 items), one measuring worry about hypoglycaemia and its negative effects (HFS-W) and the other one behaviour to avoid hypoglycaemia (HFS-B). ${ }^{28}$ In this study, only the HFS-W (18 items) was used, as the HFS-B has shown a questionable structure. ${ }^{29}$ The responses are rated on a 5-point Likert scale from 0 (never) to 4 (always), with higher scores indicating higher levels of fear related to hypoglycaemia. Internal consistency for the worry scale was satisfactory with a Cronbach's $\alpha$ of $0.87 .^{30}$

The PAID-20 questionnaire provides a total score from 0 to 100 , by summing the $0-4$ responses given for each of the 20 items and multiplying this sum by $1.25{ }^{29}$ The PAID-5 contains questions 3, 6, 12, 16 and 19 from the full PAID-20 scale. The scale gives a total score from 0 to 20 . A score of 8 and above indicates a high level of diabetes-related distress ${ }^{16}$ (online supplementary table S1).

\section{Data analysis}

Descriptive statistics were conducted to describe the sample. A CFA with maximum likelihood estimation was used to investigate the factor structure of the PAID-5 scale. Missing data for PAID- 5 were handled by listwise deletion in CFA-models; however, only two persons had missing data on at least one item. Model fit was evaluated by inspection of various goodness-of-fit measures, including model $\chi^{2}$, df and associated $\mathrm{p}$ values. In addition, a goodness-of-fit index (GFI), comparative fit index (CFI), root mean squared error of approximation (RMSEA) and standardised root mean square residual (SRMR), ratio of $\chi^{2}$ value to the $\mathrm{df}(\mathrm{CMIN} / \mathrm{DF})$ and normed fit index (NFI) were assessed. ${ }^{30} 31$ The model was considered to fit the data when the following criteria were satisfied: RMSEA $<0.08$, CFI $>0.95$, GFI $>0.90$, SRMR $<0.08$, CMIN $/$ $\mathrm{DF}<3, \mathrm{NFI}>0.95 .^{31} 32$

Convergent validity was assessed by Pearson's correlations $^{33}$ to examine the relationships between diabetes-related emotional distress (PAID-5 scores) and perceived overall health, emotional well-being (WHO-5), depression (HADS-D) and worry about hypoglycaemia (HFS-W). We also investigated how the PAID-5 scale correlated with the total PAID-20 score. Coefficients in the range of 0-0.19 were regarded as very weak, $0.2-0.39$ as weak, $0.40-0.59$ as moderate, $0.6-0.79$ as strong and $0.8-1$ as very strong correlation. ${ }^{33}$ Discriminant validity assessed whether the PAID-5 scale can differentiate between groups. Independent samples t-tests were used to compare the mean scores on the PAID-5 for people with and without diabetes long-term complications and between type 1 and type 2 diabetes. Relationships between the PAID-5 score and age, diabetes duration, treatment regimen and metabolic control (HbAlc) were explored using Pearson correlations.

The reliability of the PAID-5 scale was estimated by calculating the internal consistency and the test-retest reliability. Cronbach's $\alpha$ was used to determine internal consistency for the PAID-5 scale total scores. Test-retest reliability for the PAID- 5 scale was examined by intraclass correlation coefficient. ${ }^{34}$

Missing substitution with the mean was used for the HAD depression scale when at least 5 items of 7 were answered. ${ }^{25}$ For all other questionnaires, when less than $50 \%$ was missing, missing data were replaced with the case mean. ${ }^{35}$ Statistical Package for the Social Sciences (SPSS) V.23.0 and AMOS V.23.0 for Windows were used to analyse the data. A significance level of 0.05 was used in all analyses.

\section{Ethical considerations}

The National Committee for Medical and Health Research Ethics assessed the application (2016/1104/ REK vest) and approval was obtained from the Norwegian Center for Research Data (ref. nr. 49383). In addition, approval was obtained from the clinics where the study was conducted. Informed consent was obtained from the participants. 


\begin{tabular}{|c|c|}
\hline Characteristics & $\begin{array}{l}\text { Total sample } \\
(n=143)\end{array}$ \\
\hline \multicolumn{2}{|l|}{ Demographic variables } \\
\hline Age (years), mean $\pm S D$ & $48.9 \pm 11.9$ \\
\hline Male sex & $78(54.5)$ \\
\hline \multicolumn{2}{|l|}{ Clinical variables } \\
\hline \multicolumn{2}{|l|}{ Type of diabetes } \\
\hline Type 1 & $87(60.8)$ \\
\hline Type 2 & $56(39.2)$ \\
\hline $\mathrm{HbA}_{1 \mathrm{c}}(\%)$, mean $\pm \mathrm{SD}^{*} \dagger$ & $7.6 \pm 1.2$ \\
\hline $\mathrm{HbA}_{1 \mathrm{c}}(\mathrm{mmol} / \mathrm{mol})$, mean $\pm \mathrm{SD}^{*} \dagger$ & $60 \pm 13$ \\
\hline Diabetes duration (years), mean $\pm S D$ & $17.1 \pm 12.9$ \\
\hline \multicolumn{2}{|l|}{ Type of treatment } \\
\hline Insulin & $88(61.5)$ \\
\hline Oral medication & $28(19.6)$ \\
\hline Insulin and oral medication & $27(18.9)$ \\
\hline \multicolumn{2}{|l|}{ Episodes of serious hypoglycaemia } \\
\hline $1-3$ times in the past 6 months & $16(11.2)$ \\
\hline \multicolumn{2}{|l|}{ Self-reported complications } \\
\hline $\begin{array}{l}\text { Presence of one or more late } \\
\text { complications }\end{array}$ & $32(22.4)$ \\
\hline
\end{tabular}

Data are shown as $n$ (\%). Per cent of patients with valid values for categorical variables and mean $\pm \mathrm{SD}$ for continuous variables.

${ }^{*} \mathrm{HbA}_{1 \mathrm{c}}$ (glycated haemoglobin) measurements were reported using the International Federation of Clinical Chemistry units $(\mathrm{mmol} / \mathrm{mol})$ in addition to the derived NGSP units (\%).

$\mathrm{tn}=100, \mathrm{HbA}_{1 \mathrm{c}}$ values older than 8 weeks a prior and more than 12 weeks after filling out the survey were excluded.

$\ddagger$ Retinopathy, cardiovascular diseases or foot ulcers.

\section{Patient and public involvement}

Patients and or public were not involved in setting the research questions or planning the study. Outcomes were self-reported by patients based on predefined questions. The study had no patient advisers. Due to the nature of this validation study, feedback regarding the results was not planned for those involved.

\section{RESULTS}

\section{Demographic and clinical data}

The questionnaire was returned by 143 patients of 342 yielding a response rate of $42 \%$. Clinical and demographic characteristics are presented in table 1 . The mean age of the participants was 48.9 years (SD 11.9) (range 19-65). The mean HbAlc for the participants was $7.6 \%$ $(60 \mathrm{mmol} / \mathrm{mol})(\mathrm{SD} 1.2)$. The mean duration of diabetes was 17.9 years (SD 12.9) (range $1-54$ years). In total, 117 patients (82\%) agreed to the second assessment. The non-participants $(n=197)$ were younger than the participants (mean age 45.2 vs 48.9, $\mathrm{p}=0.006$ ), and a larger proportion was male compared with the participants. The
Table 2 Factor loadings and goodness-of-fit indices for the PAID-5 one-factor solutions

\begin{tabular}{lll}
\hline & Model 1 & Model 2 \\
\hline Standardised loadings & & \\
\multicolumn{1}{c}{ Item 3 } & 0.83 & 0.85 \\
Item 6 & 0.86 & 0.85 \\
Item 12 & 0.82 & 0.80 \\
Item 16 & 0.68 & 0.72 \\
\hline Item 19 & 0.73 & 0.72 \\
AVE & 0.62 & 0.63 \\
Composite reliability & 0.76 & 0.76 \\
Df & 5 & 4 \\
$\chi^{2}$ (p) & $14.85(0.11)$ & $6.0(0.195)$ \\
CFI & 0.974 & 0.995 \\
GFI & 0.961 & 0.984 \\
SRMR & 0.035 & 0.024 \\
RMSEA & 0.119 & 0.061 \\
CMIN/DF & 2.971 & 1.51 \\
NFI & 0.962 & 0.984 \\
\hline
\end{tabular}

Model 1: One-factor CFA, Model 2: One-factor CFA with covariance of error terms between item 3 and 16 .

$\chi^{2}(p)$ : Model $\chi^{2}$. CFI: comparative fit index (good fit $>0.95$ ). GFI: goodness of fit index (good fit $>0.90$ ); SRMR: standardised root mean square residual (good fit $<0.08$ ). RMSEA: root mean square error of approximation (acceptable fit $<0.08$ ); CMIN/DF: ratio of $\chi^{2}$ value to the df $(<3)$; NFI: normed fit index (good fit $>0.95$ ).

mean score for the PAID-5 in this study sample was 5.3 $(\mathrm{SD}=4.3)$ and individual scores ranged from 0 to 19 .

\section{Validity}

Construct validity

A CFA for PAID-5 was carried out for 141 patients (table 2). We hypothesised a one-factor model for PAID-5. After allowing the correlation between error terms between items 3 and 16 , the overall $\chi^{2}=6.0, \mathrm{df}=4$ ( $\mathrm{p}$ value of 0.195 ), showed a good model fit. Additional indices resulted as follows: RMSEA $=0.061$, CFI $=0.995$, $\mathrm{GFI}=0.984$ and $\mathrm{SRMR}=0.024, \mathrm{NFI}=0.984, \mathrm{CMIN} / \mathrm{DF}=1.51$, showing excellent fit.

\section{Convergent and discriminant validity}

There was a significant moderate correlation between the PAID-5 total score and HFS worry scale $(\mathrm{r}=0.598$, $\mathrm{p}<0.001)$. There was also a weak positive correlation between the PAID-5 scale and HAD depression scale $(\mathrm{r}=0.380, \mathrm{p}<0.001)$. Convergent validity was also confirmed by a negative correlation between the PAID- 5 and WHO-5 scale $(\mathrm{r}=-0.363, \mathrm{p}<0.001)$ and the perception of general health $(\mathrm{r}=-0.420, \mathrm{p}<0.001)$. The PAID- 5 total score also correlated significantly with the PAID-20 total score $(\mathrm{r}=0.923, \mathrm{p}<0.001)$.

There was no significant difference in PAID-5 scores between persons with type 1 diabetes (mean $=5.59$, 
$\mathrm{SD}=4.58)$ and persons with type 2 diabetes (mean $=4.95$, $\mathrm{SD}=3.93, \mathrm{p}=0.38$ ). There was also no significant difference in PAID-5 mean scores between those who reported having diabetes long-term complications (mean $=5.75$, $\mathrm{SD}=0.7)$ and those not having these complications (mean $=5.2, \mathrm{SD}=4.4, \mathrm{t}(140)=0.61, \mathrm{p}=0.54)$. Diabetes-related distress mean scores approached statistical significance when comparing patients who reported having retinopathy $(7.2, \mathrm{SD}=4.0)$ versus those without retinopathy (mean=5.1, $\mathrm{SD}=4.2, \mathrm{p}=0.06)$. Although women scored higher on the PAID-5 (mean=5.9, SD=4.6) than men (mean $=4.86, \mathrm{SD}=4.01)$, the difference was not significant $(\mathrm{p}=0.15)$.

Patients who had experienced episodes of serious hypoglycaemia in the past 6 months had a significantly higher PAID-5 mean score $(7.5(\mathrm{SD}=4.95))$ versus those who had not had these episodes $(5.0, \mathrm{SD}=4.2(\mathrm{p}=0.043))$. There were no significant differences in the PAID-5 mean scores for the three different treatment groups: insulin $(\mathrm{n}=87)$, oral medication $(\mathrm{n}=28)$ or both $(\mathrm{n}=27)(\mathrm{p}=0.90)$. There were no significant correlations with higher age and longer duration of diabetes. Higher HbAlc was positively correlated with higher PAID-5 mean scores, but the correlation was weak $(r=0.14)$ and not significant $(\mathrm{p}=0.16)$.

\section{Reliability}

Internal consistency and test-retest reliability

The Cronbach's $\alpha$ for the PAID-5 scale was 0.89. Interitem correlations for the PAID-5 scale ranged from 0.49 to 0.74 . The test-retest reliability of the PAID-5 was assessed in 92 participants who returned the repeat questionnaire and resulted in an ICC of 0.81 (95\% CI 0.70 to $0.87, \mathrm{p}<0.001)$.

\section{DISCUSSION}

The results of the current study demonstrate satisfactory psychometric properties of the short form of the PAID-5 in Norwegian adult patients with type 1 and type 2 diabetes. Our findings provide evidence for a one-factor structure for the PAID-5 scale, enabling the assessment of diabetes-related emotional distress. Convergent validity was demonstrated by statistically significant moderate correlations with other concept-related PROMs. The PAID-5 scale showed good internal consistency and a stable test-retest reliability among patients with type 1 and type 2 diabetes across three different clinics in Norway. The instrument might be considered as a supplement to guide consultations or as a screening instrument in registries and/or population health databases. Use of this tool may increase knowledge on the prevalence of diabetes-related emotional distress and thus inform guidelines for healthcare professionals and future interventions.

The Norwegian version of the PAID-5 clearly demonstrated a one-factor structure as postulated. The psychometric results in the current study lend support to findings from two previous validation studies on the PAID-5 scale. ${ }^{16} 19$ In Asia, the Korean version of the
PAID-5 enabled a one factor model and demonstrated excellent goodness-of-fit indices after the modification with the error of terms between items 3 and $6 .{ }^{17}$ Our CFA among Norwegians showed excellent goodness-of-fit indices after model modification with the covariance of error terms between items 3 and 16. Therefore, it seems that the instrument enables the assessment of diabetes-related emotional distress, although one data driven modification was needed that may have inflated the model fit.

The present study showed that the PAID-5 correlated positively with fear of hypoglycaemia (HFS) and symptoms of depression (HADS-D) and negatively with emotional well-being (WHO-5) and ones' general health perception (RAND-36), which emphasises good convergent validity. When diabetes-related stress increases, emotional wellbeing and perception of ones' general health decreases, as expected. ${ }^{16} 26{ }^{27}$ Previously, McGuire $e t a l^{16}$ demonstrated the relationship between the PAID-5 scale and the WHO-5 scale. However, there is limited evidence showing relationships with concepts of fear of hypoglycaemia and symptoms of depression. We demonstrated this in the current study, emphasising the usefulness of this brief questionnaire.

The PAID-5 scale discriminates well among those who had experienced episodes of serious hypoglycaemia in the past 6 months compared with those who had not had hypoglycaemia. The study population in general experienced a low level of diabetes-related emotional distress, as the mean score on the PAID-5 for the study population was 5.3 $(\mathrm{SD}=4.3)$. However, individual scores ranged from 0 to 19 , indicating that there were patients with a high level of diabetes-related emotional distress. Relationships between the PAID-5 scale and other subgroups were weak and non-significant. For example, women scored higher on the PAID-5 scale as expected, but this difference was not significant, probably due to the relatively small sample size as in the previous study conducted in Iceland. ${ }^{36}$ There were no significant differences between the mean PAID-5 scores for the three different treatment groups (insulin, oral medication or both) $(\mathrm{p}=0.90)$. Our relatively small sample size might be the reason, but it is also possible that type of treatment is not the main reason for a higher burden of diabetes distress. On the other hand, a higher HbAlc (as a measure of metabolic control) might be a better marker as higher HbAlc was positively correlated with PAID-5 mean scores in this study (NS) as well as in previous research. ${ }^{15}$ However, future studies specifically designed to answer these questions (eg, by use of stratified sampling or by using latent class analyses) with large sample sizes are needed to test for discrimination between different subgroups.

In the current study, the mean diabetes duration of the study population was 17.1 years and metabolic control was generally close to the treatment goals, as $50 \%$ of the participants in the subgroup had a HbAlc value of $\leq 7.3 \%$ $(56 \mathrm{mmol} / \mathrm{mol})$. In the current study, the PAID-5 scale did not discriminate between groups, such as patients with and without diabetes-related long-term complications. This might be a consequence of the relatively low number of people with complications. Nevertheless, the 
proportion of diabetes long-term complications seems reasonable for this patient group and is in line with previous research in Norway. ${ }^{1537}$

Metabolic control (HbA1c measurements) was positively, but only weakly correlated with PAID-5. This is consistent with results from PAID-20 validation studies, where diabetes-related emotional distress and glycaemic control have shown to be positively correlated-as diabetes distress increases, HbAlc level also increases. ${ }^{15} 38-40$ Although higher HbAlc values have been associated with high diabetes-related emotional distress, it should not be taken as self-evident that patients who are able to maintain an optimum blood sugar feel less distressed.

The short-form of the PAID-20, the PAID-5, showed a good internal consistency and test-retest reliability. This confirms the assumption in previous validation studies that the number of items in the PAID-20 could be reduced..$^{15}$ Our findings and previous studies of the PAID-5 scale demonstrated good to excellent internal consistency reliability, with Cronbach's $\alpha$ varying from 0.83 to $0.93 .^{6161941}$

Diabetes, which is a chronic disease, not only involves making healthy choices in one's everyday life, but one must also have the ability to see diabetes and its psychological aspects as a larger and more complex picture with many different challenges throughout life. Diabetes self-management training is closely connected to how patients understand the nature of the disease and its management, thus reducing different fears (eg, fear of hypoglycaemia), guilt and frustration and at the same time increasing skills in managing diabetes self-care and medication adherence. ${ }^{7}$

\section{Strengths and limitations}

In this well-defined sample of patients across three clinics, the Norwegian PAID-5 was shown to be a reliable and valid short questionnaire for assessing diabetes-related distress among people with type 1 or type 2 diabetes. Although the scale has demonstrated good psychometric properties, this study has limitations. Type of diabetes and metabolic control $\left(\mathrm{HbA}_{1 \mathrm{c}}\right)$ were received from the patient's medical record. However, other clinical characteristics such as diabetes complications were self-reported by the patient, which may cause inaccuracies. ${ }^{33}$ Second, the non-responders were younger than the participants, which calls for caution when interpreting the results for younger adults with diabetes. Third, the information about the study and the request for participation was sent by mail. The distribution method in this study has probably contributed to a relatively low response rate. However, we had enough power to investigate the one-dimensional scale structure with a CFA. Nevertheless, the sample size restricted us in determining if the PAID-5 scale has the ability to discriminate between different subgroups. This needs further research in a larger sample. In spite of these limitations, this cross-sectional study provides a valid assessment of the psychometric properties of the short form of the PAID scale in Norwegian adult patients with type 1 and type 2 diabetes.

\section{CONCLUSION}

In conclusion, the findings from this study provide evidence that the Norwegian version of the PAID-5 scale is a reliable and valid instrument for assessing diabetes-related emotional distress among patients with type 1 and type 2 diabetes in Norway, although its ability to discriminate between groups needs to be tested further in a larger sample. The scale has only five items and has the potential to guide communication in one-on-one consultations. Although this validation study was conducted among patients visiting their doctor or a diabetes nurse in specialty healthcare, the PAID-5 questionnaire is also relevant to use in primary healthcare.

\section{Author affiliations}

${ }^{1}$ Department of Health and Social Sciences, Institute of Health and caring Science, Western Norway University of Applied Sciences, Bergen, Norway

${ }^{2}$ Department of Nursing, School of Health and Welfare, Jonkoping University, Jonkoping, Sweden

${ }^{3}$ Department of Clinical Neurophysiology, University Hospital Linköping, Linköping, Sweden

${ }^{4}$ Department of Global Public Health and Primary Care, University of Bergen, Bergen, Norway

${ }^{5}$ Rory Meyers College of Nursing, New York University, New York City, New York, USA

Acknowledgements The author would like to thank the patients who agreed to participate in the study.

Contributors MV contributed to the study concept, project planning and management, recruitment of participants, data analysis, manuscript preparation, drafting the manuscript and approved the final manuscript. $A B$ contributed to the study concept, project planning, manuscript preparation, drafting the manuscript and approved the final manuscript. Jl contributed to data analysis, manuscript preparation, drafting the manuscript and approved the final manuscript. AV contributed to the study concept, manuscript preparation, drafting the manuscript and approved the final manuscript. MMI contributed to the study concept, project planning and management, data analysis, manuscript preparation, drafting the manuscript and approved the final manuscript.

Funding Western Norway University of Applied Sciences funded the study partly Competing interests None declared.

\section{Patient consent for publication Obtained.}

Ethics approval The National Committee for Medical and Health Research Ethics assessed the application (2016/1104/REK vest) and approval was obtained from the Norwegian Center for Research Data (ref.nr. 49383). In addition, approval was obtained from the clinics where the study was conducted. Informed consent was obtained from the participants.

Provenance and peer review Not commissioned; externally peer reviewed. Data sharing statement № additional data available.

Open access This is an open access article distributed in accordance with the Creative Commons Attribution Non Commercial (CC BY-NC 4.0) license, which permits others to distribute, remix, adapt, build upon this work non-commercially, and license their derivative works on different terms, provided the original work is properly cited, appropriate credit is given, any changes made indicated, and the use is non-commercial. See: http://creativecommons.org/licenses/by-nc/4.0/.

\section{REFERENCES}

1. International Diabetes Federation (2017). IDF diabetes atlas. 8 edn: International Diabetes Federation.

2. Ruiz PLD, Stene LC, Bakken IJ, et al. Decreasing incidence of pharmacologically and non-pharmacologically treated type 2 diabetes in Norway: a nationwide study. Diabetologia 2018;61:2310-8.

3. Skrivarhaug T, Stene LC, Drivvoll AK, et al. Incidence of type 1 diabetes in Norway among children aged 0-14 years between 1989 and 2012: has the incidence stopped rising? Results 
from the Norwegian Childhood Diabetes Registry. Diabetologia 2014:57:57-62.

4. Nathan DM, Genuth S, Lachin J, et al. The effect of intensive treatment of diabetes on the development and progression of longterm complications in insulin-dependent diabetes mellitus. $N$ Engl J Med 1993;329:977-86.

5. UK Prospective Diabetes Study (UKPDS) Group (1998). Intensive blood-glucose control with sulphonylureas or insulin compared with conventional treatment and risk of complications in patients with type 2 diabetes (UKPDS 33). UK Prospective Diabetes Study (UKPDS) Group. Lancet 1998;352:837-53.

6. Nicolucci A, Kovacs Burns K, Holt Rl, et al. Diabetes Attitudes, Wishes and Needs second study (DAWN2 ${ }^{\mathrm{TM}}$ ): cross-national benchmarking of diabetes-related psychosocial outcomes for people with diabetes. Diabet Med 2013;30:767-77.

7. Rubin RR, Peyrot M. Psychological issues and treatments for people with diabetes. J Clin Psychol 2001;57:457-78.

8. Fisher L, Gonzalez JS, Polonsky WH. The confusing tale of depression and distress in patients with diabetes: a call for greater clarity and precision. Diabetic Medicine 2014;31:764-72.

9. Fisher L, Skaff MM, Mullan JT, et al. A longitudinal study of affective and anxiety disorders, depressive affect and diabetes distress in adults with Type 2 diabetes. Diabet Med 2008:25:1096-101.

10. Fisher L, Mullan JT, Arean P, et al. Diabetes distress but not clinical depression or depressive symptoms is associated with glycemic control in both cross-sectional and longitudinal analyses. Diabetes Care 2010;33:23-8.

11. Fisher L, Polonsky WH, Hessler D, et al. A practical framework for encouraging and supporting positive behaviour change in diabetes. Diabet Med 2017;34:1658-66.

12. American Diabetes Association. American Diabetes Association Standards of Medical Care - 2016. Diabetes Care 2016;39.

13. Sturt J, Dennick K, Due-Christensen M, et al. The detection and management of diabetes distress in people with type 1 diabetes. Curr Diab Rep 2015;15:101.

14. Polonsky WH, Anderson BJ, Lohrer PA, et al. Assessment of diabetes-related distress. Diabetes Care 1995;18:754-60.

15. Graue M, Haugstvedt A, Wentzel-Larsen T, et al. Diabetes-related emotional distress in adults: reliability and validity of the Norwegian versions of the Problem Areas in Diabetes Scale (PAID) and the Diabetes Distress Scale (DDS). Int J Nurs Stud 2012;49:174-82.

16. McGuire BE, Morrison TG, Hermanns N, et al. Short-form measures of diabetes-related emotional distress: the Problem Areas in Diabetes Scale (PAID)-5 and PAID-1. Diabetologia 2010;53:66-9.

17. Lee EH, Lee YW, Lee KW, et al. Measurement of diabetes-related emotional distress using the Problem Areas in Diabetes scale: psychometric evaluations show that the short form is better than the full form. Health Qual Life Outcomes 2014;12:142.

18. Esbitt SA, Tanenbaum ML, Gonzalez JS. Disentangling Clinical Depression from Diabetes-Specific Distress: Making Sense of the Mess We've Made. Screening for depression and other psychological problems in diabetes. London: Springer, 2013:27-46.

19. Lee J, Lee EH, Kim CJ, et al. Diabetes-related emotional distress instruments: a systematic review of measurement properties. Int $J$ Nurs Stud 2015;52:1868-78.

20. Thulin LBB, Iversen MM, Hanestad BR. Translation and cultural adaptation of audit of diabetes dependence quality of life (ADDQoL) into Norwegian. Vård I Norden 2008;28:53-6.

21. Wolf EJ, Harrington KM, Clark SL, et al. Sample size requirements for structural equation models: an evaluation of power, bias, and solution propriety. Educ Psychol Meas 2013;76:913-34.
22. Hays RD, Morales LS. The RAND-36 measure of health-related quality of life. Ann Med 2001;33:350-7.

23. Zigmond AS, Snaith RP. The hospital anxiety and depression scale. Acta Psychiatr Scand 1983;67:361-70.

24. Bjelland I, Dahl AA, Haug TT, et al. The validity of the Hospital Anxiety and Depression Scale. An updated literature review. J Psychosom Res 2002;52:69-77.

25. Mykletun A, Stordal E, Dahl AA. Hospital Anxiety and Depression (HAD) scale: factor structure, item analyses and internal consistency in a large population. Br J Psychiatry 2001;179:540-4.

26. Hajos TR, Pouwer F, Skovlund SE, et al. Psychometric and screening properties of the WHO- 5 well-being index in adult outpatients with Type 1 or Type 2 diabetes mellitus. Diabet Med 2013;30:e63-9.

27. Topp CW, Østergaard SD, Søndergaard S, et al. The WHO-5 Well-Being Index: a systematic review of the literature. Psychother Psychosom 2015;84:167-76.

28. Gonder-Frederick LA, Schmidt KM, Vajda KA, et al. Psychometric properties of the hypoglycemia fear survey-ii for adults with type 1 diabetes. Diabetes Care 2011;34:801-6.

29. Welch G, Weinger K, Anderson B, et al. Responsiveness of the Problem Areas In Diabetes (PAID) questionnaire. Diabet Med 2003;20:69-72.

30. Graue M, Iversen MM, Wentzel-Larsen T, et al. Assessing fear of hypoglycemia among adults with type 1 diabetes - psychometric properties of the Norwegian version of the Hypoglycemia Fear Survey II questionnaire. Nor Epidemiol 2013;23:75-81.

31. Hooper D, Coughlan J, Mullen M. Structural equation modelling: guidelines for determining model fit. Electronic Journal of Business Research Methods 2008;6:53-60.

32. Hu Li-tze, Bentler PM. Cutoff criteria for fit indexes in covariance structure analysis: conventional criteria versus new alternatives. Structural Equation Modeling: A Multidisciplinary Journal 1999:6:1-55.

33. Polit DF, Beck CT. Nursing research: generating and assessing evidence for nursing practice. 9 edn. Philadelphia, Pa: Wolters Kluwer Health, 2012

34. Fayers PM, Machin D. Quality of life: the assessment, analysis and interpretation of patient-reported outcomes. 2 edn. Chichester: John Wiley, 2007.

35. Polit DF. Statistics and data analysis for nursing research. 2nd edn. Upper Saddle River, NJ: Pearson, 2010.

36. Sigurdardottir AK, Benediktsson R. Reliability and validity of the Icelandic version of the Problem Area in Diabetes (PAID) Scale. Int J Nurs Stud 2008;45:526-33.

37. Iversen MM, Midthjell K, Østbye T, et al. History of and factors associated with diabetic foot ulcers in Norway: the Nord-Trøndelag Health Study. Scand J Public Health 2008;36:62-8.

38. Papathanasiou A, Koutsovasilis A, Shea S, et al. The Problem Areas in Diabetes (PAID) scale: psychometric evaluation survey in a Greek sample with type 2 diabetes. J Psychiatr Ment Health Nurs 2014;21:345-53.

39. Beléndez M, Hernández-Mijares A, Marco J, et al. Validation of the Spanish version of the Problem Areas in Diabetes (PAID-SP) Scale. Diabetes Res Clin Pract 2014;106:e93-5.

40. Amsberg S, Wredling R, Lins PE, et al. The psychometric properties of the Swedish version of the Problem Areas in Diabetes Scale (SwePAID-20): scale development. Int J Nurs Stud 2008;45:1319-28.

41. Nicolucci A, Rossi MC, Pellegrini F, et al. Benchmarking network for clinical and humanistic outcomes in diabetes (BENCH-D) study: protocol, tools, and population. Springerplus 2014;3:83-9. 